\title{
Evaluation of Blood Transfusions in Anemic Children in Effia Nkwanta Regional Hospital, Sekondi-Takoradi, Ghana
}

\author{
Verner N. Orish, Alex Ilechie, Theophilus Combey, Onyekachi S. Onyeabor, Chuku Okorie, and Adekunle O. Sanyaolu* \\ Department of Internal Medicine, Effia-Nkwanta Regional Hospital, Sekondi-Takoradi, Ghana; Department of Optometry, \\ University of Cape Coast, Cape Coast, Ghana; Department of Biomedical and Forensic Science, University of Cape Coast, Cape Coast, Ghana; \\ Department of Community Health and Preventive Medicine, The Satcher Health Leadership Institute, Morehouse School of Medicine, \\ Atlanta, Georgia; Department of Epidemiology and Biostatistics, Saint James School of Medicine, Anguilla, British West Indies; \\ Department of Medical Microbiology and Immunology, Saint James School of Medicine, Anguilla, British West Indies
}

\begin{abstract}
Blood transfusion is a common practice in sub-Saharan Africa as a way of correcting anemia in children with mild and severe sicknesses. This study evaluated this practice in a secondary health-care institution in Ghana. A retrospective study was done over a 3-year period from January 2010 to December 2012. Medical records of children admitted, successfully treated, and discharged from the hospital were collected and analyzed. Data were analyzed using Epi Info version 7. Transfusions were more among male children $(89,63.1 \%)$ than female children $(52,36.9 \%)$. The highest number of blood transfusions were carried out on children in the age range $0-1$ year $(66,46.8 \%)$. The majority of the blood transfusions were done on children with hemoglobin concentration level of $5 \mathrm{~g} / \mathrm{dL}$ and below. Children with malaria parasitemia $(83,58.9 \%)$ had more transfusions than children without malaria parasitemia $(58,41.1 \%)$. Fever alone $(43,30.5 \%)$ and fever with gastrointestinal symptoms $(33,23.4 \%)$ were the predominant symptoms among children who had blood transfusions. In conclusion, younger children received more transfusions than older children. Also, male children received more blood transfusions than female children. Malaria was observed as a major contributory factor to the requirement for blood transfusions among the children.
\end{abstract}

\section{INTRODUCTION}

Blood transfusions are common therapeutic practices for adult and pediatric patients in hospitals and clinics in subSaharan Africa. They are also very frequently used in combating severe anemia in children. ${ }^{1}$ Despite their frequent use, there are understandable concerns about the safety of the use of blood and blood products in a region already burdened with blood-borne pathogens. ${ }^{2}$ Transfusion-transmitted infections are major challenges for public health in Africa. Prevalence rates of transfusion-transmitted infections such as hepatitis B and C, human immunodeficiency virus (HIV), and syphilis are ranked among the highest worldwide. ${ }^{3}$ Blood transfusions have been implicated in $10-15 \%$ of HIV transmissions in sub-Saharan Africa. ${ }^{4}$

In countries such as Cameroon, Republic of Congo, Gabon, Ghana, and Nigeria, the prevalence of sickle-cell disease is between $20 \%$ and $30 \%$ whereas in some parts of Uganda it is as high as $45 \% .^{5}$ Besides hookworm infections, nutritional deficiencies, and hemoglobinopathies, malaria is one of the major causes of anemia in children. ${ }^{6}$ In Ghana, 3.5 million people contract malaria every year and approximately 20,000 children die of malaria every year $(25 \%$ of the deaths of children under the age of five). ${ }^{7}$

Anemia is common in malaria-endemic areas, particularly in young children. Severe anemia is suspected clinically from pale mucosal surfaces and palms and confirmed by measurement of hemoglobin $(\mathrm{Hb})$ concentration or packed cell volume. Severe anemia is defined as an $\mathrm{Hb}<5 \mathrm{~g} / \mathrm{dL}$ or a hematocrit of $<15 \%$ in children (age $<12$ years) and an $\mathrm{Hb}<7 \mathrm{~g} / \mathrm{dL}$ or a hematocrit of $<20 \%$ in adults. Severe anemia occurs most commonly in young children in areas of moderate and high

* Address correspondence to Adekunle O. Sanyaolu, Department of Medical Microbiology Immunology, Saint James School of Medicine, Albert Lake Drive, The Quarter, A-1 2640, Anguilla, British West Indies. E-mail: ksanyaolu@mail.sjsm.org malaria transmission. Many deaths in children with severe malarial anemia occur within 48 hours of admission, with $25-50 \%$ occurring within 6 hours. Anemia develops rapidly and transfusion is often required. ${ }^{8}$ Severe anemia in subSaharan African children is a major cause of admission to the hospital as well as a leading cause of mortality. It is also responsible for the estimated 660,000 malaria-related deaths that occur yearly. ${ }^{9}$

The choice to transfuse a child is entirely up to the physician or caregiver and is usually based on national guidelines, which are often derived from the World Health Organization (WHO) guidelines. This choice is usually influenced by laboratory and/or physical findings regarding the sick child. Although there is a standard guideline for transfusions, most caregivers often deviate from these guidelines. ${ }^{10,11}$ Most times they rely only on laboratory results that show low $\mathrm{Hb}$ concentration to make decision on transfusion. In sub-Saharan Africa, adherence to guidelines and transfusion recommendations varies between countries. ${ }^{9}$

Severe malaria is defined by clinical or laboratory evidence of vital organ dysfunction. ${ }^{12}$ WHO guideline recommends that children with $\mathrm{Hb}<5 \mathrm{~g} / \mathrm{dL}$ warrant transfusion if they have respiratory distress or cardiovascular instability. This is a general policy. However, children with severe malaria or high parasite counts and $\mathrm{Hb}<5 \mathrm{~g} / \mathrm{dL}$ will usually have a further drop in $\mathrm{Hb}$, so transfusion will usually be necessary. Thus, the recommended transfusion threshold in severe malaria is $5 \mathrm{~g} / \mathrm{dL}$ and not $4 \mathrm{~g} / \mathrm{dL}$ for children in areas of moderate or high transmission. ${ }^{13}$

There have been some improvements in blood transfusion services in the region since the advent of HIV with regard to advancements in infrastructure for screening services and storage technique. ${ }^{4}$ Despite these improvements, there is still a need to evaluate blood transfusion practices in this region, not only to avoid transmission of diseases but to avoid iatrogenic complications that sometimes follow blood transfusion in children; especially if adept clinical judgments are not used. Thus, it is important to take a closer look at the blood 
transfusion practices of physician and caregivers in this region. Few published data on blood transfusion of anemic children in sub-Saharan Africa exist; thus, findings from this study on categories of children who received blood transfusions will provide a guide for the evaluation of blood transfusion practices in the region. The main objective of this study is to evaluate blood transfusions in anemic children at Effia Nkwanta Regional Hospital, Sekondi-Takoradi, western Ghana.

\section{METHODOLOGY}

This is a retrospective study carried out on children that were seen in the accident and emergency department and later admitted to the children's ward of the Effia Nkwanta Regional Hospital.

Study site. Sekondi-Takoradi Metropolis is a twin city in the western region of Ghana. The western region is located in the southern part of Ghana. It has 22 districts, which are subdivisions of 13 major districts.

Sekondi-Takoradi is located at $04^{\circ} 55^{\prime} 0^{\prime \prime} \mathrm{N}, 1^{\circ} 46^{\prime} 0^{\prime \prime} \mathrm{W}$. Twin city can be defined as two cities with geographical proximity where there is interchange of people, goods, and services. It is within the Shama Ahanta east and west metropolitan area. It is the administrative capital of the western region, has a land mass of approximately $385 \mathrm{~km}^{2}$, and is strategically located in the southwestern part of Ghana, about $242 \mathrm{~km}$ to the west of Accra, the capital city. It is also approximately $280 \mathrm{~km}$ from the La Cote d'lvoire border in the west. It has an estimated population of 445,205 inhabitants ${ }^{14}$ and is Ghana's third largest city, an industrial and commercial nerve center, which attracts many tourists annually.

Effia Nkwanta Regional Hospital is a secondary health institution and is the only referral hospital for the whole western region. It is located at the Sekondi-Takoradi Metropolis. It is a referral center for all the hospitals within the 22 districts of the region.

Data collection. Records of the pediatric emergency patients that were seen at the Effia-Nkwanta regional hospital and admitted to the children's ward, where necessary, were used for this retrospective study. Information of admitted children was recorded in the admission register. Data for this study were retrieved from the admission record of the accident and emergency unit of the hospital. Data were double entered using Microsoft Excel spreadsheet (Microsoft Corp., Redmond, WA). Children admitted with fever, gastrointestinal symptoms, and cough over the study period were included in this study. Their medical records were searched and retrieved. Only children who were successfully treated and discharged were included in this study. Records relating to the demographics of the patients, as well as clinical and laboratory findings, were retrieved. Clinical information included other symptoms accompanying fever, as well as information on blood transfusions during admission. Laboratory results for malaria parasite test and $\mathrm{Hb}$ concentration level were obtained. Information on length of stay in the hospital and treatments received were collected and utilized for the study.

Classifications of patients with malaria admitted in the hospital were according to the WHO criteria for mild and severe malaria. ${ }^{12}$ Malaria parasite diagnoses in this facility were done using Plasmodium falciparum-specific rapid diagnostic test kits (Premier Medical Corporation Ltd., Mumbai, India) and microscopy using Giemsa staining technique. The rapid response kit detects $P$. falciparum antigens, and the presence of two lines in the text kit indicates $P$. falciparumpositive result. Malaria parasite positive results were confirmed with thick and thin peripheral blood smears stained with Giemsa and examined under the microscope using $\times 100$ power fields under oil immersion objective lens. Hb estimation and white cell count were done as part of the complete blood count from an automated blood-cell analyzer machine (Sysmex Hematology Analyzer; Sysmex, Kakogawa, Japan).

Data analysis. The results obtained were analyzed using Epi info version 7 (Centers for Disease Control and Prevention, Atlanta, GA). Frequency distribution for the variables was estimated using percentages for malaria parasite and $\mathrm{Hb}$, symptoms and days of stay, and $\mathrm{Hb}$ and days of stay. Student's $t$ test was used to compare means of, days of stay for males and females, $\mathrm{Hb}$ level for males and females, and malaria parasitemia for males and females, while Pearson $\chi^{2}$ and Fisher's exact test were used to test the statistical significance of the categorical variables. Multivariable regression analysis was done to test for the association between length of stay in hospital and factors that could affect it such as degree of anemia, malaria illness, age, and sex. All tests were two tailed. $P$ values less than 0.05 were considered significant.

\section{RESULT}

A total of 1,145 children were admitted, successfully treated, and discharged over the 3-year study period. Among these, 141 children had blood transfusions $(12.3 \%)$. In this study, the mean age of children for transfusion was 2.5 years (standard deviation \pm 2.31 )

In this study, 89 male $(63.1 \%)$ and 52 female $(36.9 \%)$ children were transfused. Blood transfusions were higher among children in the age range $0-1$ year $(66,46.9 \%)$. This was followed by children within the age range of 2 and 5 years $(57,40.4 \%)$. Majority of children that received blood transfusion

TABLE 1

Clinical and demographic characteristics of children who received blood transfusion

\begin{tabular}{|c|c|c|}
\hline Variables & Frequency & Percentage \\
\hline \multicolumn{3}{|l|}{ Sex } \\
\hline Male & 89 & 63.1 \\
\hline Female & 52 & 36.9 \\
\hline \multicolumn{3}{|l|}{ Age (years) } \\
\hline $0-1$ & 66 & 46.8 \\
\hline $2-5$ & 57 & 40.4 \\
\hline $6-11$ & 18 & 12.8 \\
\hline \multicolumn{3}{|l|}{ Hemoglobin (g/dL) } \\
\hline$<5$ & 66 & 46.8 \\
\hline $5-7$ & 64 & 45.4 \\
\hline$\geq 8$ & 11 & 7.8 \\
\hline \multicolumn{3}{|l|}{$\mathrm{Mp}$} \\
\hline No $\mathrm{Mp}$ & 58 & 41.1 \\
\hline Mp present & 83 & 58.9 \\
\hline \multicolumn{3}{|l|}{ Symptoms } \\
\hline None & 10 & 7.1 \\
\hline Fever & 43 & 30.5 \\
\hline Gastro & 5 & 3.5 \\
\hline Fever + gastro & 33 & 23.4 \\
\hline Cough & 3 & 2.1 \\
\hline Fever + cough & 22 & 15.6 \\
\hline Gastro + cough & 4 & 2.8 \\
\hline All three symptoms (fever + gastro + cough $)$ & 21 & 14.9 \\
\hline
\end{tabular}

$\mathrm{Mp}=$ malaria parasite 
had their $\mathrm{Hb}$ concentration below $5 \mathrm{~g} / \mathrm{dL}$ (127, 46. 81\%) (Table 1). More children received blood transfusions with positive malaria parasite test $(83,58.9 \%)$ than those with negative test for malaria parasite $(58,41.1 \%)$. Among children that received blood transfusions, the predominant symptoms were fever $(43,30.5 \%)$, fever and gastrointestinal disturbances (33, $23.4 \%)$, fever and cough $(22,15.6 \%)$, and combination of fever, cough, and gastrointestinal disturbances $(21,14.9 \%)$ (Table 1).

No significant difference $(P>0.05)$ was recorded in the age categories of children who received blood transfusions by sex, $\mathrm{Hb}$ level, and days of stay in the hospital. Also, no significant difference $(P>0.05)$ was recorded in the $\mathrm{Hb}$ levels of children who received transfusions by sex and length of stay in the hospital. Finally, no evidence of an association $(P>0.05)$ was recorded with multivariate analysis that looked at the factors that affects the length of stay in hospital such as degree of anemia, malaria illness, age, and sex.

\section{DISCUSSION}

This study retrospectively evaluated blood transfusions practices in Effia Nkwanta Regional Hospital, from January 2010 to December 2012 by looking at the records of pediatric emergency patients that were seen, treated, and discharged or admitted for further treatment.

More male children had blood transfusions than female children in this study. This finding differs from the result obtained in a study carried out at the Children's National Medical Center, Washington, DC, where the percentages of female and male that had blood transfusions were the same. ${ }^{15}$

A total of $12.3 \%$ of children received blood transfusions in the 3-year period under study. Comparing this study to a similar study done at the Children's National Medical Center, a total of $4.8 \%$ of children received blood transfusions over a 3 -year period, that is, 2001-2003. ${ }^{15}$ The percentage of children that had blood transfusions in this study was higher than those at the Children's hospital in Washington, DC. The most likely reason for the higher transfusions rate recorded in this study as compared with the study in Washington, DC, is the higher burden of disease and malnutrition among children in sub-Saharan African region, which predisposes them to anemia and subsequent blood transfusions. ${ }^{13}$

In a similar study carried out among children presenting to six hospitals in malaria-endemic regions of Uganda, Kenya, and Tanzania, of the 3,082 children, majority (76\%) were anemic on admission while one-third (33\%) were severely anemic. The prevalence of severe anemia varied from $12 \%$ in Kenya to between $23 \%$ and $43 \%$ in Uganda. In this study, almost half of all patients were transfused including $94 \%$ of those with severe anemia. ${ }^{9}$

The mean age of children that received blood transfusions in this study (2.5) is lower than that of the Children's hospital (5.5) in Washington. Children in Africa are obviously exposed to diseases that predispose them to anemia and malaria at an early age when compared with children in developed countries. ${ }^{16}$

Among children that received blood transfusions in this study, majority had $\mathrm{Hb}$ levels less than $5 \mathrm{~g} / \mathrm{dL}$ before blood transfusion. This is an obvious good practice as the WHO classifies severe anemia in children less than 12 years of age as $\mathrm{Hb}$ levels below $5 \mathrm{~g} / \mathrm{dL}{ }^{12}$ However, $\mathrm{Hb}$ level is not the only criteria for selecting children for blood transfusions, the clinical state of the child should also be considered. In this study, clinical guideline for blood transfusion was not documented; hence, it is difficult to measure compliance with the WHO transfusion guidelines.

Eighty three children with malaria parasite infection had blood transfusion as compared with those without malaria parasite infection. Malaria has been vigorously linked to anemia, especially severe anemia. ${ }^{13,16}$ In the study carried out among children presenting to six hospitals in malaria-endemic regions of Uganda, Kenya, and Tanzania, malaria parasitemia was present in $57 \%$ of children, with a higher proportion of anemic children having parasitemia compared with non-anemic children. ${ }^{9}$ This might be considered as one of the reasons why most children with malaria infection have more blood transfusions than those without malaria infection. In this study, the most common symptoms of malaria recorded were fever and gastrointestinal symptoms; this thus explains why these symptoms were seen in most of the children who had blood transfusion.

\section{STUDY LIMITATIONS}

The exclusion of children who died during the period under study is a major limitation to this study as it restricted the study from fully assessing the mortality associated with anemia-related malaria during the study. In addition, limited information exists for transfusion guidelines and practices in this hospital, and guidelines used for diagnosing anemia in this study were not documented; hence, the need for a knowledge, attitude, and practices of current international transfusion guidelines among doctors in the hospital. Also, information on outcome of transfusion such as adverse reaction was not provided aside that the patient was successfully treated and discharged. Finally, retrieved data did not show whether transfusion was done more than once.

\section{CONCLUSION}

This study showed that majority of children that were admitted in the children's ward of the Effia Nkwanta Regional Hospital and received blood transfusions had malaria infection. Although the choice of blood transfusions in children in relation to the level of anemia in this study was within standard international practices, further studies are required to evaluate international best practices among physicians in the hospital for optimum transfusion management as well as the requirement for blood transfusion in anemic children in the region.

Received April 22, 2015. Accepted for publication December 8, 2015. Published online January 19, 2016.

Authors' addresses: Verner N. Orish, Department of Internal Medicine, Effia-Nkwanta Regional Hospital, Sekondi-Takoradi, Ghana, E-mail: orishv@yahoo.com. Alex Ilechie, Department of Optometry, University of Cape Coast, Cape Coast, Ghana, E-mail: drilechie@ yahoo.com. Theophilus Combey, Department of Biomedical and Forensic Science, University of Cape Coast, Cape Coast, Ghana, E-mail: theo.combey@gmail.com. Onyekachi S. Onyeabor, Department of Community Health and Preventive Medicine, The Satcher Health Leadership Institute, Morehouse School of Medicine, Atlanta, GA, E-mail: sonyeabor@msm.edu. Chuku Okorie, Department of Epidemiology and Biostatistics, Saint James School of Medicine, 
Anguilla, British West Indies, E-mail: cokorie@mail.sjsm.org. Adekunle O. Sanyaolu, Department of Medical Microbiology and Immunology, Saint James School of Medicine, Anguilla, British West Indies, E-mail: ksanyaolu@mail.sjsm.org.

\section{REFERENCES}

1. Lacritz EM, Campbell CC, Ruebush TK, Hightower AW, Wakube W, Steketee RW, Were JBO, 1992. Effect of blood transfusion on survival among children in a Kenyan hospital. Lancet 340: $524-528$.

2. Tagny CT, Mbanya D, Tapko JB, Lefrère JJ, 2008. Blood safety in sub-Saharan Africa: a multi-factorial problem. Transfusion 48: 1256-1261.

3. Pruett CR, Vermeulen $M$, Zacharias $P$, Ingram $C$, Tagny CT, Bloch EM, 2015. The use of rapid diagnostic tests for transfusion infectious screening in Africa: a literature review. Transfus Med Rev 29: 35-44.

4. Fleming AF, 1997. HIV and blood transfusion in sub-Saharan Africa. Transfus Sci 18: 167-179.

5. World Health Organization (Africa), 2015. Sickle Cell Disease Prevention and Control. Available at: http://www.afro.who .int/en/ghana/ghana-publications/1775-sickle-cell-disease.html. Accessed August 19, 2015.

6. Sarpong N, Owusu-Dabo E, Kreuels B, Fobil JN, Segbaya S, Amoyaw F, Hahn A, Kruppa T, May J, 2015. Prevalence of malaria parasitaemia in school children from two districts of Ghana earmarked for indoor residual spraying: a cross-sectional study. Malar J 14: 260.
7. UNICEF Ghana, 2007. Malaria. UNICEF Ghana Fact Sheet. Available at: http://www.unicef.org/wcaro/WCARO_Ghana_ Factsheet_malaria.pdf. Accessed August 19, 2015.

8. Anonymous, 2014. Severe malaria. Trop Med Int Health 19: 7-131.

9. Kiguli S, Maitland K, George EC, Olupot-Olupot P, Opoka RO, Engoru C, Akech SO, Nyeko R, Mtove G, Reyburn H, Levin M, Babiker AG, Gibb DM, Crawley J, 2015. Anaemia and blood transfusion in African children presenting to hospital with severe febrile illness. BMC Med 13: 21.

10. Roseff SD, Luban NL, Manno CS, 2002. Guidelines for assessing appropriateness of pediatric transfusion. Transfusion 42: 1398-1413.

11. Sacher RA, Luban NLC, Strauss RG, 1989. Current practice and guidelines for the transfusion of cellular blood components in the newborn. Transfus Med Rev 3: 39-54.

12. World Health Organization, 2012. Management of Severe Malaria: A Practical Handbook, 3rd edition. Available at: http://apps .who.int/iris/bitstream/10665/79317/1/9789241548526_eng.pdf. Accessed April 16, 2015.

13. Obonyo CO, Vulule J, Akhwale WS, Grobbee DE, 2007. In-hospital morbidity and mortality due to severe malarial anemia in western Kenya. Am J Trop Med Hyg 77 (Suppl 6): 23-28.

14. Wikipedia, 2013. Sekondi-Takoradi. Available at: http://en.wikipedia .org/wiki/Sekondi-Takoradi. Accessed April 15, 2015.

15. Slonim AD, Joseph JG, Turenne WM, Sharangpani A, Luban NLC, 2008. Blood transfusions in children: a multi-institutional analysis of practices and complications. Transfusion 48: 73-80.

16. Brabin BJ, Premji Z, Verhoeff F, 2001. Analysis of anemia and child mortality. J Nutr 131: 636S-645S. 